https://idp.uoc.edu

ARTÍCULO

\title{
Admisibilidad (o no) de la mediación familiar en contextos de violencia y una particular referencia a la situación en Portugal*
}

\author{
Rossana Martingo Cruz \\ Escola de Direito da Universidade do Minho
}

Fecha de presentación: enero de 2021

Fecha de aceptación: mayo de 2021

Fecha de publicación: octubre de 2021

\section{Resumen}

La mediación familiar es uno de los métodos privilegiados de resolución alternativa de litigios en el ámbito de los conflictos familiares. Estos están dotados de características emocionales que los hacen más adecuados a un contexto extrajudicial. Y, al mismo tiempo, son de una complejidad humana que obliga a un análisis distinto en el contexto de la mediación.

También es cierto que no todos los conflictos familiares son susceptibles de mediación, manteniendo los tribunales tradicionales toda su relevancia. Sin embargo, cada vez con mayor frecuencia se vislumbran las ventajas de un método autocompositivo en la búsqueda de una solución que responda a los intereses y deseos de aquellos que, durante un tiempo, compartieron otra experiencia de proximidad e intimidad.

Surge la cuestión de si una pareja que pasó por episodios de violencia puede o no acogerse a la mediación familiar. Los autores y profesionales de la mediación parecen no compartir la misma postura al respecto. Es importante percibir cuáles son los argumentos utilizados en esta divergencia. Al final, prestaremos especial atención al caso portugués.

\section{Palabras clave}

mediación familiar, violencia familiar, conflictos familiares, resolución alternativa de litigios, Convenio de Estambul

\footnotetext{
* Parte de este estudio fue presentado oralmente en Las Jornadas Argentino-Luso-Brasileñas sobre Daños y Violencia, que ocurrió en los días 25 y 26 de abril de 2019, en Buenos Aires, Argentina.
} 


\title{
The (in)admissibility of family mediation in contexts of violence and a special refe-rence of the Portuguese regime
}

\begin{abstract}
Mediation is one of the alternative dispute resolution methods (ADR) that is considered especially suitable in the sphere of family conflicts. These are endowed with emotional characteristics that make them more appropriate to be held in a different context than in the judicial forum. And, at the same time, they are of a human complexity that requires a different analysis in the context of mediation. Also, it is true that not all family conflicts will be subject to mediation, which means the traditional justice forums (the courts) maintain all their relevance. However, the advantages of a 'selfcompositional' method are undeniable in the search for a solution that responds to the interests and desires of those who, in another time, shared another experience of proximity and intimacy.

It is questioned whether a couple who have experienced violence may or may not be eligible for family mediation. The authors and practitioners of the mediation seem not to have the same position on this matter. It is important to perceive the arguments used in this divergence. Also, towards the end, we will pay special attention to the Portuguese case in this regard.
\end{abstract}

\section{Keywords}

family mediation, family violence, family conflicts, alternative dispute reso-lution (ADR), Istanbul Convention 


\section{Introducción}

La mediación familiar, como medio de resolución alternativa de litigios, ha tenido una gran aplicabilidad en la búsqueda de consenso en los conflictos familiares. Estos tienen una configuración propia en comparación con otros litigios que ocupan los tribunales. Además, existe un componente emocional que debe ser gestionado, junto con el contenido jurídico aplicable.

La especificidad de la realidad familiar convierte el derecho de familia en una rama del Derecho en constante cambio (para acompañar la evolución social) y obliga a que los escenarios donde las contiendas familiares se presenten también sean capaces de gestionar el continuo desarrollo.

La mediación familiar surge, en este contexto, de la bús queda de mejores soluciones para las crisis familiares. Esta, aunque no es la solución a todos los problemas que se derivan de la familia, se convierte en un medio adecuado para una amplia mayoría de los problemas familiares.

A veces, la escalada del conflicto familiar alcanza extremos graves. ¿Es la mediación familiar aceptable y aconsejable cuando la brecha relacional alcanza su límite, máxime en el caso de violencia entre las partes? Existe una divergencia entre los autores en cuanto a este análisis, siendo un punto debatido en la práctica internacional de la mediación familiar. Tengamos en cuenta que abordaremos el tema de la mediación familiar en situaciones de violencia familiar y no entraremos en la discusión sobre la mediación penal en este tipo de delitos ${ }^{1}$. Estas son situaciones diferentes, el objetivo de la mediación familiar es distinto al de la mediación penal. En la mediación familiar se busca el consenso y acuerdo entre las partes, una restauración de la comunicación para que las partes puedan, muchas veces, seguir conviviendo, por ejemplo, en interés de sus hijos menores. En la mediación penal, «lo que se pretende es conseguir una solución en la que la víctima se sienta reparada en el daño por el hecho punible (...)» (Carrizo González-Castell, 2017, pág. 253).

En este texto solo nos centraremos en la posibilidad de la mediación familiar en situaciones de violencia también en el ámbito familiar. Así pues, no se trata de analizar el problema de la mediación penal: esta no es admitida en Portugal para delitos públicos, delitos más graves, donde está incluida la violencia doméstica (art. 152 del Código Penal portugués) ${ }^{2}$. Además, también en España, la Ley Orgánica 1/2004, de 28 de diciembre, de Medidas de Protección Integral contra la Violencia de Género, ha obstaculizado la mediación en casos de violencia ${ }^{3}{ }^{4}$. Sin embargo, en este texto estudiamos la posibilidad de la mediación familiar en situaciones de separación o divorcio, ante parejas que han vivido episodios de violencia. Pero la mediación no surge en el ámbito de los procesos penales que pueden, o no, haber existido. La mediación familiar en Portugal tiene un diseño distinto al de la mediación penal ${ }^{5}$. $Y$ no es esa la problemática que nos ocupa. La discusión es más dogmática: ¿será ventajosa la mediación familiar en casos de separación o divorcio, cuando las partes han vivido situaciones de violencia?

Intentaremos abordar tal problemática partiendo del sistema portugués y observando lo que otros sistemas defienden al respecto.

1. Particularmente en Portugal, ambas son muy distintas y, por eso, solo abordaremos la cuestión del uso de la mediación familiar en casos de violencia en escenario familiar.

2. Véase la Ley portuguesa $n .^{\circ} 21 / 2007$, de $12 / 6$, que determina, en el artículo 2, que la mediación penal solo puede existir si los delitos son objeto de denuncia (delitos semipúblicos) o son objeto de acusación privada (delitos particulares). El delito de violencia doméstica es un delito público y, por eso, no le es aplicable la Ley de Mediación Penal.

3. «La aprobación de dicha norma condujo a la doctrina a afirmar de forma mayoritaria que, efectivamente, la implementación de mecanismos de justicia restaurativa -concretamente de la mediación penal- había dejado de ser normativamente posible en supuestos de violencia de género entre íntimos en nuestro ordenamiento jurídico» (Villacampa, 2020, pág. 49).

4. Para la reparación de la víctima y mediación penal, desde la óptica de la justicia restaurativa, véase Carrizo González-Castell (2017, pág. 251 y sigs.).

5. Aunque la Ley de Mediación general es la misma (Ley n. ${ }^{0}$ 29/2013, 19/4), la mediación familiar está regulada en el Orden Normativo 13/2018, de 9 de noviembre; y la mediación penal se encuentra en la Ley de 2007 mencionada en la nota 2. 


\section{Mediación familiar}

Los medios alternativos de resolución de controversias son mecanismos extrajudiciales que surgen como una respuesta complementaria a los medios tradicionales de justicia. Los medios tradicionales empezaron a resultar insuficientes e ineficaces, y fue necesario buscar otras opciones, más adecuadas a determinadas disputas. (Gouveia, 2018, pág. 34; y Castillejo Manzanares, 2011, pág. 341) ${ }^{6}$.

La tutela judicial efectiva ya no implica necesariamente un derecho de acceso a los tribunales, incluso puede significar eludir la propia jurisdicción (Cebola, 2013, pág. 74 y sigs.). En otras palabras, el acceso a la justicia ya no significa acceso directo e inmediato a los tribunales. Pueden y deben desarrollarse instancias que permitan una eventual antesala o un nuevo foro, y es imprescindible fomentar una visión integral de la Justicia como pilar del Estado de derecho.

Vislumbremos la mediación. En la mediación, un tercero independiente, neutral e imparcial (el mediador) ayuda a las partes a buscar consenso, tratando de restablecer la comunicación y el diálogo.

El mediador coloca a las partes en el centro de la solución del conflicto que las enfrenta, y les proporciona las herramientas necesarias para que puedan resolver su disputa mediante un acuerdo que realmente les satisfaga. El mediador asume que las partes son las personas más competentes para encontrar las respuestas a las preguntas importantes de su vida, brindándoles las herramientas necesarias para que puedan resolver su disputa?.

La mediación familiar es una forma de resolución alternativa de disputas que busca autorresolver los conflictos, es decir, la parte del problema también es parte de la solución. En la medida en que pretende rescatar la comunicación, es la vía más adecuada para resolver las controversias derivadas de relaciones duraderas, como las familiares. Por todo lo anterior, es un medio adecuado para solucionar conflictos de una gran carga emocional. Tal como explica García-Perrote Martínez: «[u]n conflicto familiar es aquella situación donde los integrantes del conjunto de personas ascendientes, descendientes y colaterales- emparentadas entre sí, o con algunos miembros, por vínculos sanguíneos, adoptivos o afines y que pueden vivir juntos, son, en apariencia, irreconciliables o no alcanzables en el corto plazo y de forma simultánea por ser mutuamente excluyentes. Es decir, se trata de un conflicto interpersonal, al afectar a diferentes personas, y, a la vez, intragrupo, porque surge entre integrantes del mismo colectivo» (2020, pág. 170).

El objetivo de la mediación es, fundamentalmente, la reestructuración de la relación, recuperar la cordialidad necesaria para la convivencia, de ahí que la mediación sea un mecanismo privilegiado de resolución de conflictos en disputas derivadas de relaciones duraderas, como las disputas familiares. También la mediación familiar supone un ahorro económico en relación con la vía jurisdiccional para la resolución de conflictos de pareja o hijos (Martín Diz, 2017, pág. 71). Pero el enfoque no debe ser solamente reducir los costes económicos y sí fomentar la cordialidad y el respeto entre las personas y buscar soluciones favorables para todos los miembros de la familia.

\section{Mediación y violencia familiar}

Se ha discutido mucho sobre si puede existir mediación familiar cuando la relación entre los mediados está viciada con episodios de violencia. Es un tema polémico dentro de la mediación familiar (Brown y Marriot, 2005, pág. 239).

Aunque la violencia en la familia es tan antigua como esta, la noción de violencia doméstica y la percepción de su entorno criminal nace en la década de 1970, en el desarrollo de la investigación de mujeres maltratadas en Estados Unidos (Dias, 2004, pág. 91). En este concepto de violencia

6. No todos los autores están de acuerdo con su valor añadido a la Justicia: «Me limito por tanto a señalar dos puntos que considero muy importantes: a) contrariamente a lo que muchos piensan, el creciente uso de formas de ADR no es un factor positivo, sino la señal evidente de la crisis de la justicia ordinaria: es un signo de patología, no de salud del sistema procesal; b) también, contrariamente a lo que muchos piensan, no todo es bueno en el ámbito de los ADR» (Taruffo, 1999, pág. 316).

7. Para más estudios y detalles sobre la autocomposición, cfr. Alcalá-Zamora y Castillo (1991, pág. 57 y sigs.). 
se integran diferentes tipos de abusos cometidos sobre los miembros de la familia ${ }^{8}$ (por regla general, cualquier acto, omisión o amenaza que provoque daños físicos, psicológicos o emocionales a personas con las que existen relaciones familiares, legales o de hecho) ${ }^{9}$. A los efectos de este trabajo, y sin perjuicio de la referencia legal al delito de violencia doméstica en Portugal, tendremos en cuenta la noción dada en el artículo 3 apartado b del Convenio de Estambul: «por "violencia doméstica" se entenderán todos los actos de violencia física, sexual, psicológica o económica que se producen en la familia o en el hogar o entre cónyuges o parejas de hecho antiguos o actuales, independientemente de que el autor del delito comparta o haya compartido el mismo domicilio que la víctima».

Si una pareja con una convivencia marcada por la violencia recurre a la mediación familiar, es esencial que el mediador logre medir esta realidad lo antes posible, analizando si la mediación puede o no continuar. La mediación familiar, como medio de resolución alternativa de litigios parte de la idea de paridad entre los mediados. Es decir, ambos estarán en una posición de igualdad, no pudiendo existir un ascendente de uno sobre el otro, lo que puede inviabilizar la mediación. Solo si las partes se sienten libres en las sesiones de mediación, pueden transmitir sus intereses de forma serena y clara. Esta será la mayor dificultad práctica cuando existe un historial de violencia familiar, pues difícilmente existirá un equilibrio de fuerzas entre los mediados.

Cornelius y Faire advierten de situaciones en las que existen verdaderas víctimas que necesitan ser protegidas y que los mediadores deben ser sensatos y prudentes a la hora de actuar como rescatadores (2007, pág. 194).

La mediación es un instrumento de paz social y, según algunos autores, puede ser ventajosa en situaciones conflictivas como en los casos de violencia familiar, en la medida en que promueva el diálogo. Para ellos, sería esencial que ambas partes participen de forma intrínsecamente voluntaria en la mediación y perciban las ventajas de este medio de resolución alternativa de litigios. Al mismo tiempo, podría proporcionar una mayor satisfacción a las víctimas el hecho de que, a diferencia del sistema de justicia común, la víctima se convierta en protagonista del conflicto y adquiera una visión global del conflicto (Villacampa, 2020, pág. 57). La misma autora tiene un aporte novedoso y relevante sobre la propuesta de mediación en casos de violencia, respondiendo a algunos miedos que normalmente se señalan: «Al respecto, quizá convendría aclarar que cualquier supuesto de violencia de género puede ser objeto de mediación, no solamente aquellos que consistan en el uso ocasional de la violencia. Incluso los casos de empleo de violencia habitual podrían ser derivados a un mecanismo alternativo de resolución de conflictos siempre que pudiera acabarse garantizando el equilibrio de fuerzas de las partes en el proceso, lo que debería decidirse caso por caso. Admitida la posibilidad en abstracto, se debe atender a que uno de los temores manifestados en cuanto a la operatividad de los procesos de mediación en tales supuestos es el posible desequilibrio de poder entre las partes. Garantizarlo para asegurar que la decisión de acudir a la mediación ha sido efectivamente libre y voluntaria y que ambas partes, pero especialmente la mujer, están en condiciones de acudir a la misma en un modo en que puedan mantener una mínima asertividad, debe constituir un objetivo prioritario» (Villacampa, 2020, pág. 65).

Sin embargo, debemos tener en cuenta que existen varios riesgos asociados que pueden agravarse al permitir una convivencia entre el agresor y la víctima. Puede incluso ser una forma de perpetuar el temor y la amenaza cuando se propician encuentros después de la separación. Igualmente, en ocasiones, la frustración derivada del intercambio de ideas con el otro mediado y el mediador puede acarrear más tensión y conflictividad. La seguridad y el bienestar de las partes es condición sine qua non de la mediación familiar. Por otro lado, no se espera que la víctima se sienta libre y esperanzada para alcanzar un acuerdo con su agresor. En realidad, «[V]ictims of domestic violence might be incapable of directly participating in mediation or even recognizing the full extent of their harm due to the psychological scars of battering or by a fear that participating in mediation might provoke the batterer to engage in retaliatory violence during or after the session» (Murphy y Rubinson, 2008, pág. 404). En la misma

8. Para Llamas Pombo, la violencia doméstica es una herida visible de la familia de la era de la globalización, de la posmodernidad (2020, pág.16).

9. Sobre definiciones de violencia, véanse Murphy y Rubinson (2008, pág. 406) y Dias (2004, págs. 91-94). 
dirección, «[p]or otra parte, si se ha producido violencia de género y la mujer decide interrumpir la relación de pareja, llevar a cabo un proceso de mediación familiar con víctima y agresor para que alcancen acuerdos sobre los términos de su separación, está completamente contraindicado» (Arias, 2015, pág. 125).

Pues aquí se encuentra la mayor dificultad. Si no existe voluntariedad y confianza, no valdrá la pena iniciar la mediación. Además de que, en ciertas situaciones, creemos que la relación ha alcanzado un punto de ruptura tan grave que será imposible restaurar el diálogo y esperar un consenso.

Al mismo tiempo, en estos casos la conflictividad ha alcanzado tal nivel de exacerbación que la mediación no sería apropiada. En Portugal aún no existe mucha discusión sobre el tema de la mediación familiar. Distinto es el caso de la mediación penal que, como ya se ha mencionado, no se admite en casos de violencia doméstica ${ }^{10}$. Pero abordaremos el caso portugués más adelante.

\section{Regulación legal comparada: algunas referencias a la regulación española (nacional y autonómica) y la regulación europea}

Ahora haremos consideraciones más generales sobre la mediación familiar y la violencia, con algunas referencias al derecho comparado, en particular del ordenamiento español. Serán, todavía, referencias individuales, ya que el objeto de este texto no es el análisis del régimen español.

Cárdenas desaconseja la práctica de la mediación en estas situaciones de desequilibrio por convertirse en una mera «oficialización» del divorcio (1998, págs. 67-68). Lo esencial será, en primer lugar, asegurarse de que la violencia no persiste. Por otra parte, este es un límite al principio de la confidencialidad del mediador, y este puede poner fin inmediatamente a la mediación. Por ejemplo, la Ley 4/2001, de 31 de mayo, reguladora de la mediación familiar de la comunidad autónoma de Galicia, establece que «[s]e interrumpirá, o en su caso no se iniciará, cualquier proceso de mediación familiar cuando en él esté implicada una mujer que sufriera o sufra violencia de género» (art. 8, n. ${ }^{\circ}$ 4. Cabe señalar además que en España -a diferencia de Portugal- existe una autonomía de la violencia de género"1. Además, posteriormente, la Ley Orgánica 1/2004, de 28 de diciembre, de Medidas de Protección Integral contra la Violencia de Género, obstaculizó la mediación en casos de violencia.

También Cárdenas diferencia los «casos de violencia» de los «casos con violencia». Si, en el momento en que los cónyuges se dirigen a la mediación familiar, esto ya no ocurre, parece aceptar la posibilidad de mediación (1998, pág. 212). Sin embargo, Rebecca Morley defiende que es raro que la violencia se agote en un evento aislado, normalmente se prolonga en el tiempo y, a la vez aumenta en intensidad (2001, pág. 207)

Sin perjuicio de opiniones discordantes, la mayoría de la doctrina rechaza la posibilidad de mediación familiar en casos de violencia doméstica, entendiendo que el mediador no solo debe dar la misma por terminada, sino que además debe denunciar dicha violencia a las autoridades (Wilde y Gaibrois, 2003, pág. 72). Por lo demás esta situación puede establecer un límite al principio de confidencialidad al que el mediador está obligado.

La mediación no cumplirá su fin cuando los mediados no puedan estar en presencia del otro controlando la rabia asociada al conflicto, o cuando exista una afasia emocional, o incluso cuando exista miedo de alguna de las partes. Pues, en este caso, su actitud estará condicionada al temor de una reacción. De ahí la reticencia de la mayoría de los mediadores a proseguir con la mediación en estos casos: «[I]os mediadores no deberían intervenir en aquellos casos en los que pueda haber sospecha de delito, así como en aquellos otros en los que se intuya la existencia de afecciones psicológicas necesitadas de la intervención de médicos, psiquiatras y terapeutas» (Vinyamata Camp, 2003, pág. 34).

10. Para la mediación penal y la violencia doméstica en Portugal, cfr. Santos (2010, pág. 67 y sigs.).

11. Sobre la definición, véase Lopéz Vale (2014, pág. 42). Sobre violencia de género y violencia doméstica en Argentina, cfr. Medina (2013, pág. 36 y sigs.). 
Por otra parte, tampoco en Galicia la mediación familiar puede iniciarse o continuar cuando exista violencia. Por ejemplo, «(...) se interrumpirá, o en su caso no se iniciará, cualquier proceso de mediación familiar cuando en él esté implicada una mujer que sufriera o sufra violencia de género. Ley 11/2007 relativa a la violencia de género de Galicia» (García Presas, 2009, pág. 197).

Asimismo, la Ley 1/2006, de 6 de abril, de Mediación Familiar de Castilla y León establece en el artículo 2 que: «[q] uedan expresamente excluidos de la mediación familiar los casos en que exista violencia o maltrato sobre la pareja, los hijos, o cualquier miembro de la unidad familiar». También, la Ley n. ${ }^{0}$ 1/2001, de 15 de marzo, de Cataluña, en el artículo 22 bis, consagra que: «Debe interrumpirse o, si procede, no debe iniciarse cualquier proceso de mediación de pareja o familiar en que esté implicada una mujer que haya sufrido o sufra violencia física, psíquica o sexual en la relación de pareja» ${ }^{12}$. En el mismo sentido de inadmisibilidad van otras leyes autonómicas, como la de la Comunidad de Madrid, etc. (cfr. Blanco Carrasco, 2009, pág. 173).

Como sabemos, en España existe prohibición legal de mediación en situaciones de violencia de género por la Ley Orgánica 1/2004, de 28 de diciembre, de Medidas de Protección Integral contra la Violencia de Género ${ }^{13}$. Todavía, se cuestiona si no se deberían discutir nuevas posibilidades: «Además, sitúa a España en una posición que comienza a resultar normativamente singular respecto de la de otros países de nuestro entorno jurídico, que paulatinamente han ido admitiendo la implementación de mecanismos de justicia restaurativa en supuestos de violencia de género. De futuro, pues, también en este país resultaría adecuado que se revisase la referida prohibición legal y se normase sobre este particular, razón por la que en estas páginas se propone cuál debería ser el contenido básico de un programa restaurativo aplicable a supuestos de violencia de género» (Villacampa, 2020, pág. 49).

Como hemos visto, esta postura de no admitir la mediación familiar en situaciones de violencia intrafamiliar se refleja en varios textos legales. Por ejemplo, el Código Civil francés consagra la mediación tanto en el contexto del divorcio (art. 255/1) como en el caso de la patria potestad (art. 373-2-10); pero salvaguarda que este no sería el caso si existieran alegaciones de violencia entre los padres o hacia el niño, o cuando exista un claro ascendente de uno de los padres sobre el otro.

Además de los textos legales nacionales, Europa, a través de la Recomendación N. R (98) 1 del Comité de Ministros a los Estados Miembros sobre la Mediación Familiar (aprobada por el Consejo de Ministros el 21 de enero de 1998), ya tenía una preocupación con esta posibilidad de violencia, estableciendo que el mediador debe tener especialmente en cuenta si la violencia ha ocurrido en el pasado o se puede producir en el futuro entre las partes, y el efecto que esto pudiera tener en las posiciones de negociación de las mismas, y si, en estas circunstancias, el proceso de mediación es apropiado (Principio III.IX de la Recomendación N.ํ R [98]1).

Es decir, no ofrece una respuesta clara sobre la admisibilidad de la mediación en las situaciones de violencia, dejando esto al criterio de los mediadores y de los Estados (que pretenden incluir estas situaciones en sus legislaciones).

A su vez, la Directiva 2008/52/CE del Parlamento Europeo y del Consejo, de 21 de mayo de 2008, sobre ciertos aspectos de la mediación en asuntos civiles y mercantiles, garantiza que un límite de la confidencialidad de la mediación es la necesidad de prevención de daños a la integridad física o psicológica de una persona (art. 7).

En el mismo sentido, el Convenio del Consejo de Europa sobre prevención y lucha contra la violencia contra la mujer y la violencia doméstica (Convenio de Estambul), en el artículo 48, prohíbe los modos alternativos obligatorios de resolución de conflictos, incluida la mediación, en lo que respecta a todas las formas de violencia: «Prohibición de modos alternativos obligatorios de resolución de conflictos o imposición de condenas. 1. Las Partes adoptarán las medidas legislativas o de otro tipo necesarias para prohibir los modos alternativos obligatorios de resolución de conflictos, incluidas la mediación y la conciliación, en lo que respecta a todas las formas de violencia incluidas en el ámbito de aplicación del presente Convenio».

12. Este artículo 22 bis fue introducido por la Ley 5/2008, de 24/4.

13. Sobre esta imposibilidad, cfr. Fernández López (2015, pág. 372 y sigs.). La misma autora hace análisis de la Directiva 2012/29/EU y su carácter en la justicia restaurativa (ibid., pág. 85 y sigs.). Recordemos además la Ley general 5/2012, de 6/7, de mediación en asuntos civiles y mercantiles. Sobre su importancia en el derecho privado, cfr. Martín Diz (2017, pág. 88 y sigs.). 


\section{Análisis del régimen portugués}

El primer texto legal normativo sobre mediación familiar en Portugal aparece en 1997, mediante la Orden n. 0 12368/97 del Ministro de Justicia, del 9/12. Esta primera expresión legislativa aparece esencialmente con carácter experimental, ya que estaba destinada exclusivamente a los conflictos derivados de la regulación del ejercicio de la patria potestad y únicamente en la ciudad de Lisboa. Solo en 2007, con la Orden n.o 18778/2007, de 22/8, de la Secretaría de Estado de Justicia, se creó el Sistema de Mediación Familiar (SMF). El legislador amplió el ámbito territorial de la mediación familiar en Portugal y su competencia material a otros conflictos familiares (art. 4 de la Orden n. ${ }^{0}$ 18778/2007). Más recientemente, esta Orden de 2007 fue revocada por la Orden Normativa n. ${ }^{0}$ 13/2018, y es la Orden de 2018 que debemos tener en cuenta actualmente.

Además de esta Orden específica sobre mediación familiar de 2018, Portugal también cuenta con una ley general de mediación (Ley n. 29/2013, de 19/4). Ambos textos legales consagran los principios a respetar, tales como: voluntariedad, confidencialidad, igualdad, exigibilidad, imparcialidad, independencia, flexibilidad, proximidad, etc. (cfr. arts. $3 .^{\circ}$ a 9. ${ }^{\circ}$ de la Ley de 2013; y art. 2 de la Orden de 2018). Tanto la Ley de 2013 como la Orden de 2018 ya se han beneficiado de las enseñanzas de la Directiva 2008/52 / CE del Parlamento Europeo y del Consejo, de 21 de mayo de 2008, sobre determinados aspectos de la mediación en materia civil y mercantil.

En Portugal, la Ley n.²9/2013 de 19/4 define la mediación como la forma de resolución alternativa de controversias, realizada por entidades públicas o privadas, a través de la cual dos o más partes en la controversia buscan voluntariamente llegar a un acuerdo con la asistencia de un mediador de conflictos (apartado a) del art. 2).

Veamos ahora el tema de la violencia doméstica y la mediación familiar. En Portugal, la violencia doméstica es un delito que va más allá de la esfera privada y se considera una plaga social, que genera preocupación y tiene dimensión pública ${ }^{14}$, por lo que el hecho de que se permita la mediación no podrá subvertir su índole. No se pretende dar una respuesta infalible (porque los entornos familiares están en constante transformación y no se puede pretender contar con la mejor solución para cada problema y cada familia), pero se plantea que, por regla general, sea desaconsejable la mediación familiar en situaciones de violencia. Incluso para salvaguardar la seguridad de la víctima. La violencia no siempre termina con la separación, a menudo las consecuencias son peores. En 2019, en Portugal se registraron 24.793 delitos de violencia doméstica o situaciones análogas ${ }^{15}$.

Al no ser una cuestión pacífica en el entorno de la mediación, hay quien entiende que la mediación nunca podrá tener lugar cuando exista un historial de violencia. Otros la recomiendan siempre que se garantice el bienestar de la víctima y su seguridad; y otros, incluso, propugnan la mediación como una forma de que la víctima recupere el control que había perdido ${ }^{16}$.

Además de la violencia doméstica, otras situaciones causan una desproporción de fuerzas entre los mediados (comportamientos adictivos, enfermedades mentales,

14. Para un estudio del delito de violencia doméstica en Portugal, véase Morais (2019, pág. 33 y sigs.); Figueiredo (2020, pág. 99 y sigs.); Loureiro (2014, pág. 271 y sigs). El artículo 152 del Código Penal portugués prevé el delito de violencia doméstica («1. Quem, de modo reiterado ou não, infligir maus tratos físicos ou psíquicos, incluindo castigos corporais, privações da liberdade e ofensas sexuais: a) Ao cônjuge ou ex-cônjuge; b) A pessoa de outro ou do mesmo sexo com quem o agente mantenha ou tenha mantido uma relação de namoro ou uma relação análoga à dos cônjuges, ainda que sem coabitação; c) A progenitor de descendente comum em $1 .{ }^{\circ} \mathrm{grau}$; ou d) A pessoa particularmente indefesa, nomeadamente em razão da idade, deficiência, doença, gravidez ou dependência económica, que com ele coabite; é punido com pena de prisão de um a cinco anos, se pena mais grave Ihe não couber por força de outra disposição legal»). Este es un delito público desde el año 2000 (Ley n. ${ }^{\circ}$ 7/2000 de 27/5); por lo tanto no requiere denuncia por parte de la víctima, es suficiente el conocimiento por parte de las autoridades. Este delito fue objeto de modificaciones en 2007 para ampliar sus destinatarios a los ex de las parejas: «O que parece ter estado em causa no alargamento do âmbito de aplicação do crime de violência doméstica aos maus tratos sobre ex-cônjuges ou ex-companheiros é a necessidade político-criminal de reagir aos comportamentos retaliatórios e fortemente perturbadores da paz do ex-parceiro perpretados por aquele que não se conforma com o fim da relação ou não o suporta ver assumir um novo projecto de vida autónomo» (Brandão, 2010, pág. 13).

15. Disponible en https://www.pordata.pt/.

16. Para un análisis más completo véase Lopes y Patrão (2014, págs. 39-46) y Murphy y Rubinson (2008, págs. 401-402). 
maltrato infantil, etc.) y, en estos casos, la mediación familiar no será aconsejada (Guerra, 2006, pág. 242).

En Portugal, la Ley n. ${ }^{0}$ 141/2015, de 8/9, regula los procedimientos de tutela civil de los menores y en ella se establece la posibilidad de mediación familiar (art. 24). En la versión original, nada en particular en esta ley preveía la inadmisibilidad de mediación en caso de violencia. No obstante, en 2017 (con la Ley 24/2017, de 24/5), el legislador portugués añadió a la Ley n. ${ }^{\circ}$ 141/2015, de 8/9, el artículo 24-A, que establece como un límite a la admisibilidad del recurso a la mediación familiar cuando se haya decretado una medida coercitiva o se haya impuesto una sanción accesoria de prohibición de contacto entre padres, o si pusiera en cuestión los derechos y la seguridad de las víctimas de violencia doméstica $u$ otras formas de violencia en el contexto familiar (como abuso infantil o abuso sexual). Este cambio legislativo se deriva del artículo 48, n. ${ }^{0}$ 1 del Convenio del Consejo de Europa para la Prevención y el Combate de la Violencia contra la Mujer y la Violencia Doméstica, comúnmente Ilamado Convenio de Estambul, que prohíbe medios alternativos obligatorios para resolver disputas en estos casos.

Al mismo tiempo, en el caso portugués, respecto al mediador, queda suspendido su deber de confidencialidad cuando la integridad física de alguien esté en cuestión ${ }^{17}$, y así lo determina el artículo 5, n. ${ }^{\circ}$ 3, de la Ley n. ${ }^{\circ}$ 29/2013, de 19/4. Lo más importante es garantizar que no persistan las situaciones de violencia, ni se cree un ambiente favorable a las mismas. No hay duda de que, si los episodios violentos persisten, la mediación debe cesar (si ya ha comenzado) y la situación transmitida a las autoridades; la duda puede surgir cuando la violencia doméstica ya no está «activa».

En cualquier caso, el hecho de que los incidentes ya no ocurran no significa que el temor físico y psicológico no estén presentes, lo que, por sí solo, es suficiente para desaconsejar la mediación familiar.

En este breve texto no hemos realizado un análisis de jurisprudencia, ya que esta no existe en el ordenamiento portugués en la materia. La mediación familiar es aún escasa en Portugal, y la cuestión de la violencia se ha discutido en la doctrina, pero no en los tribunales. Para hacernos una idea de la escasez a la que nos referimos, en el primer semestre de 2020 en Portugal hubo 420 solicitudes en el sistema público de mediación familiar y 0 (cero) solicitudes en el sistema público de mediación penal. En todo el año de 2019, hubo 700 solicitudes en el sistema público de mediación familiar y 0 (cero) solicitudes en el sistema público de mediación penal ${ }^{18}$. Así pues, resulta muy difícil hacer estudios de campo o conclusiones muy profundas, los datos son escasos y la mayor parte de la doctrina portuguesa tampoco profundiza en el tema.

\section{Conclusión}

Este texto solo trata de plantear algunas problemáticas inherentes a la mediación familiar y la violencia familiar. La percepción de que la mediación familiar es siempre apropiada en los conflictos familiares no corresponde a la realidad. No siempre es la solución más adecuada.

Las situaciones de extremo litigio o donde se ha desencadenado violencia pueden no ser adecuadas para la mediación ${ }^{19}$. Debemos considerar violencia diferentes tipos de abusos cometidos sobre los miembros de la familia, o sea, todos los actos de violencia física, sexual, psicológica o económica que se producen en la familia o en el hogar o entre cónyuges o parejas de hecho antiguos o actuales. Como fue analizado, el Convenio de Estambul, en el artículo 48, prohíbe los modos alternativos obligatorios de

17. Sobre los límites al principio de confidencialidad por parte del mediador, véase Lopes y Patrão (2014, pág. 38 y sigs.); y Cruz (2018, pág. 54 y sigs.).

18. Las estadísticas oficiales están disponibles en https://estatisticas.justica.gov.pt/sites/siej/pt-pt/Paginas/Mediacao.aspx.

19. Sin prejuicio de que, al menos en teoría, sea posible siempre que exista cuidado y especialización por parte del mediador: «[a] este respecto, el trabajo del facilitador con las partes, pero especialmente con la que tiene una posición más débil, podría resultar determinante. Eso requiere, por supuesto, de la especialización de los equipos de mediación, dado que la mediación practicada por personas escasamente especializadas, aunque voluntariosas, puede poner a las mujeres en situaciones de riesgo elevado, al no saber reconocer las señales de peligro hacia la seguridad de las mujeres y ni siquiera ser capaces de identificar manipulaciones del proceso que pueden estarse llevando a cabo por el maltratador durante el desarrollo de las sesiones» (Villacampa, 2020, pág. 66). Comprendemos y estamos de acuerdo, pero, si no existe tal capacitación, los riesgos son altos. 
resolución de conflictos, incluida la mediación, en lo que respecta a todas las formas de violencia. Sin embargo, la referencia es a los modos alternativos obligatorios. ¿Y si es la voluntad de las partes?

Como ya fue mencionado, en el régimen portugués, la regla es no admitir la mediación cuando la integridad física de alguien esté en cuestión. No hay una sola interpretación cuando existió violencia en el pasado pero ahora ya no existe. El mediador podrá evaluar la situación concreta y ver si los beneficios superan los riesgos ${ }^{20}$. Comprobando, por ejemplo, si la víctima se siente capacitada de llegar a un acuerdo con su exagresor; si la mediación traerá un verdadero sentimiento de satisfacción por el closure y un clean break; si ya no hay miedo de estar delante del otro, etc. Pero si la violencia física, psicológica o económica aún puede estar en juego, la mediación no debe avanzar. Además, no será efectiva. Asimismo, la mediación puede no ser efectiva cuando una de las partes todavía siga negan- do la ruptura de la relación, ya que esa visión desfasada de la realidad puede atenuar la correcta apreciación de las cuestiones objeto de discusión.

Al mismo tiempo, el mediador debe ser consciente de su papel de facilitador de la comunicación y fomentador del diálogo; si bien no es un reconciliador de las partes, pues no es esa su función y corre el riesgo de no contar con la formación necesaria para ejercer una función que no le corresponde. Analizamos el tema desde el ordenamiento jurídico portugués, con algunas referencias de derecho comparado $y$, en conclusión, creemos que los riesgos asociados a la perpetuidad de la violencia e intimidación deben, en la mayoría de los casos, descartar la mediación en ocurrencias de violencia familiar. Además, con un historial de violencia arduamente existirá una verdadera libertad de elegir el mejor acuerdo y la mediación podrá no alcanzar su propósito.

20.Proponiendo sugerencias para superar algunos de los riesgos, como la mediación indirecta, la mediación subrogativa, la mediación online, etc., véase Villacampa (2020, pág. 67). Sin embargo, recordamos que esta contribución de Villacampa tiene en mente la mediación penal, no la familiar. Todavía será aplicable mutatis mutandis. 


\section{Referencias bibliográficas}

ALCALÁ-ZAMORA Y CASTILLO, N. (1991). Proceso, autocomposición y autodefensa. 3. a ed. Santiago de Chile: Instituto de Investigaciones Jurídicas de la UNAM.

ARIAS, F. (2015). «Aproximación a la violencia de género desde una perspectiva psicológica». En: SOLETO MUÑOZ, H. (ed.). Violencia de género: tratamiento y prevención. Madrid: Editorial Dykinson.

BLANCO CARRASCO, M. (2009). Mediación y sistemas alternativos de resolución de conflictos: una visión jurídica. Madrid: Editorial Reus.

BOWMAN, C. (2008). «Legal treatment of cohabitation in United States». Marriage and cohabitation. [s/I]: Ashgate. [en línea] https://scholarship.law.cornell.edu/facpub/148/[Fecha de consulta: 8 de junio de 2021].

BRANDÃO, N. (2010). «A tutela penal especial reforçada da violência doméstica». Julgar, núm. 12. [en línea] http://julgar.pt/wp-content/uploads/2015/10/009-024-Tutela-especial-VD.pdf [Fecha de consulta: 8 de junio de 2021].

BROWN, H. J.; MARRIOT, A. (2005). ADR principles and practice. Londres: Thomson.

CÁRDENAS, E. (1998). La mediación en conflictos familiares: lo que hay que saber. Buenos Aires: Editorial Lumen/Hvmanitas.

CARRIZO GONZÁLEZ-CASTELL, A. (2017). «Reparación de la víctima y mediación penal». En: MARTíN DIZ, F. (dir.); CARRIZO GONZÁLEZ-CASTELL, A. (cord.). Mediación en la Administración de Justicia: implantación y desarrollo. Coruña: Andavira.

CASTILLEJO MANZANARES, R. (2011). «Mediación en el ámbito familiar». En: SOLETO MUÑOZ, H. (dir.); CARRETERO MORALES, E.; RUIZ LÓPEZ, C. (coords.). Mediación y resolución de conflictos: técnicas y ámbitos. Madrid: Tecnos.

CEBOLA, C. M. (2013). La mediación. Madrid: Marcial Pons.

CORNELIUS, H.; FAIRE, S. (2007). Tú ganas / yo gano, todos podemos ganar: cómo resolver conflictos creativamente. [s/I]: Gaia Ediciones.

CRUZ, R. M. (2018). Mediação familiar como meio complementar de Justiça. Coimbra: Almedina.

DIAS, I. (2004). Violência na família: uma abordagem sociológica. Oporto: Afrontamento.

FERNÁNDEZ LÓPEZ, M. A. (2015). La mediación en procesos por violencia de género. Cizur Menor. Pamplona: Thomson Reuters-Aranzadi.

FIGUEIREDO, S. (2020). O crime de violência doméstica: o bem jurídico. Violência doméstica: implicações sociológicas, psicológicas e jurídicas do fenómeno. Manual pluridisciplinar. 2. ${ }^{a}$ ed. Lisboa: Centro de Estudos Judiciários.

GARCÍA PRESAS, I. (2009). La mediación familiar: una alternativa en el proceso judicial de separación y divorcio. Madrid: La Ley.

GARCÍA-PERROTE MARTÍNEZ, I. (2020). «Mediación en conflictos familiares: ¿es un método adecuado para resolver este tipo de controversias?». En: GALLARDO RODRÍGUEZ, A.; ESTANCONA PÉREZ, A. A.; BERTI DE MARINIS, G. (coords.). Los nuevos retos del Derecho de Familia. Valencia: Tirant lo Blanch.

GOUVEIA, M. F. (2018). Curso de resolução alternativa de litígios. 3. a ed. Coimbra: Almedina.

GUERRA, P. (2006). Resolução alternativa de litígios. Colectânea de textos publicados na Newsletter $D G A E$. Lisboa: Ministério da Justiça-Agora Comunicação. 
HERRING, J. (2013). Family law. 6. a ed. Harlow: Pearson. DOI: https://doi.org/10.4324/9781843924487

LLAMAS POMBO, E. (2020). «Presentación: Retos del Derecho de Familia. Conferencia inaugural del I Congreso de Jóvenes Civilistas Ivs Civile Salmanticense». En: GALLARDO RODRÍGUEZ, A.; ESTANCONA PÉREZ, A. A.; BERTI DE MARINIS, G. (coords.). Los nuevos retos del Derecho de Familia. Valencia: Tirant lo Blanch.

LOPES, D.; PATRÃO, A. (2014). Lei da mediação comentada. Coimbra: Almedina.

LÓPEZ VALE, A. (2014). «Violencia de género: posible revisión a partir de la noción de estigma femenino». En: CASTILLEJO MANZANARES, R. (dir.); SANDE MAYO, M. a J.; TORRADO TARRÍO, C. (coords.). Justicia restaurativa y violencia de género: más allá de la Ley Orgánica 1/2004. Santiago de Compostela: Ed. Universidad de Santiago de Compostela.

LOUREIRO, F. N. (2014). «A violência doméstica: reflexão sobre o enquadramento legislativo português»». En: FERREIRA MONTE, M. et al. Estudos em comemoração dos 20 anos da Escola de Direito da Universidade do Minho. Coimbra: Coimbra Editora.

MARTÍN DIZ, F. (2017). «Mediación en la Administración de Justicia: balance actual y perspectivas de futuro». En: MARTíN DIZ, F. (dir.); CARRIZO GONZÁLEZ-CASTELL, A. (cord.). Mediación en la Administración de Justica: implantación y desarrollo. Coruña: Andavira.

MEDINA, G. (2013). Violencia de género y violencia doméstica: responsabilidad por daños. Buenos Aires: Rubinzal-Culzoni Editores.

MORAIS, T. (2019). Violência doméstica. Coimbra: Almedina.

MORLEY, R. (2001). «Is law reform a solution to domestic violence?». En: SOTTOMAYOR, M.a C.; JOÃO TOMÉ, M. (coords.). Direito da família e política social. Porto: Publicações Universidade Católica.

MURPHY, J. C.; RUBINSON, R. (2008). «Domestic violence and mediation: responding to the challenges of crafting effective screens. En: FREEMAN, M. (ed.). Domestic violence, the family, law \& society. [s/I]: Ashgate.

SANTOS, C. C. (2010). «Violência doméstica e mediação penal: uma convivência possível?». Julgar, núm. 12. [en línea] http://julgar.pt/wp-content/uploads/2015/10/067-079-VD-e-media\%C3\%A7\%C3\%A3o-penal.pdf [Fecha de consulta: 8 de junio de 2021].

TARUFFO, M. (1999). «Racionalidad y crisis de la Ley procesal». Doxa. Cuadernos de Filosofía del Derecho, núm. 22. [en línea] DOI: https://doi.org/10.14198/DOXA1999.22.13 [Fecha de consulta: 8 de junio de 2021].

VILLACAMPA, C. (2020). «Justicia restaurativa en supuestos de violencia de género en España: situación actual y propuesta político-criminal». Política Criminal, vol. 15, núm. 29. DOl: https://doi. org/10.4067/S0718-33992020000100047 [Fecha de consulta: junio de 2021].

VINYAMATA CAMP, E. (2003). Aprender mediación. Barcelona: Paidós.

WILDE, Z. D.; GAIBROIS, L. M. (2003). O que é a mediação. Lisboa: Agora Publicações. 


\title{
Cita recomendada
}

MARTINGO CRUZ, Rossana (2021). «Admisibilidad (o no) de la mediación familiar en contextos de violencia y una particular referencia a la situación en Portugal». IDP. Revista de Internet, Derecho y Política, núm. 33 (octubre). UOC [Fecha de consulta: dd/mm/aa] http://dx.doi.org/10.7238/idp.v0i33.380181

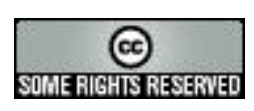

\begin{abstract}
Los textos publicados en esta revista están -si no se indica lo contrario- bajo una licencia Reconocimiento-Sin obras derivadas 3.0 España de Creative Commons. Puede copiarlos, distribuirlos y comunicarlos públicamente siempre que cite su autor y la revista y la institución que los publica (IDP. Revista de Internet, Derecho y Política; UOC); no haga con ellos obras derivadas. La licencia completa se puede consultar en: http://creativecommons.org/ licenses/by-nd/3.0/es/deed.es.
\end{abstract}

\section{Sobre la autora}

Rossana Martingo Cruz

rmartingocruz@direito.uminho.pt

Escola de Direito da Universidade do Minho

Campus de Gualtar, 4710-057 Braga (Portugal)

Profesora auxiliar invitada en la Escola de Direito da Universidade do Minho (Portugal). Profesora adjunta invitada en la Escola Superior de Gestão del Instituto Politécnico do Cávado e do Ave (Portugal). Doctora en Derecho por la Escola de Direito da Universidade do Minho (Portugal). Máster en Derecho de las Personas y Familia por la Faculdade de Direito da Universidade de Coimbra. Investigadora integrada del JusGov (Centro de Investigação em Justiça e Governação). Autora de publicaciones y ponente en congresos y conferencias de Derecho de Familia, Sucesiones y Mediación. 